\title{
Promotion of Polycentric Settlement (Growth Centre) for Sustainable Development
}

\author{
Kabi Prasad Pokhrel* \\ Geography, Tribhuvan University, Nepal \\ *Corresponding author: Kabi Prasad Pokhrel, Geography, Research Division, Tribhuvan University, Kirtipur, Nepal
}

Submission: 監: June 02, 2018; Published: 鮆June 13, 2018

\section{Introduction}

The economic, spatial and mobility trends in Nepal point towards the inevitability of developed dense and compact human settlement in the countryside with a view to materialize the social innovation and cultural practices in the sphere of existing state- of the -art and creativity. To solve the local development problems in the context of rural areas, satisfaction of human needs, diffusion of skills and technology by activating local politics and policy making for valorisation of territorial specity through democratic governance of local development is to be the prime focus for national development policy framework. It could be paradigm shift to promote the practice of self-determination economy as people transform their livelihoods and lives by enlarging the power and competence base of localities. In this context, polycentric centers growth process is considering as the engine of economic growth, social change and science and technological development in the journey of sustainable development.

Therefore the initiations of polycentric settlement network or growth pole development play significant role to promote the spatial development practices and contribute to the sustainable development of rural communities across the globe. Some important contributions are discussed here in brief.

\section{Helping backward areas catch up}

Several external and internal peripheries can be found in the north-south and east-west parts of Nepal, where the inhabitants' living conditions and opportunities are extremely poor because of high levels of unemployment, insufficient accessibility and extensive poverty. These are constantly increasing, often leading to rural segregation. It is important to eliminate serious spatial disparities in the accessibility of public services, resources and favorable living conditions that are fundamental in determining equal opportunities in society. It is typical for the whole country that the most qualified segments of the labor force and the investments searching for locations find suitable conditions predominantly in large scales and their closer vicinity. Therefore, a greater share of the educated citizens and a disproportionately large part of economic activities concentrate in polycentric centers and their surroundings which results in less sustainable and rather unbalanced (homocentric) spatial development triggering also substantial commuting.

\section{Harmonious regions and areas}

Our province, regions and territories have to function as sustainable systems of their own. These areas manage not only to preserve their values, heritage, resources and their internal coherence but also strengthen these, as long as these regions are able to maintain harmonious relationships between their societies, economies and natural-environmental, cultural elements within their local-spatial systems. The sustainability of the spatial structure and the spatial connections are fundamental preconditions for economic stakeholders and social actors to operate in a sustainable manner. Uncoordinated urban sprawl around large cities can be mentioned as examples which go hand in hand with suburbanization. Its adverse effects manifest not only in the decrease of natural and open areas, but in the daily commuting needs of the locals, the disruption of ecological networks and even in tensions in transport, financial and monetary costs and social segregation.

\section{Sustainable land use}

It is important that regulations, different development projects, as well as settlement planning encourage wise management and safe forms of land use ensuring equal opportunities which guarantees free access to important public places, helps the mitigation of commuting and transport pressure, and at the same time ensures enough natural areas and public space for citizens.

\section{Regional public utility systems, eco-technology, renewable energies}

Generating autonomous local systems that are adapted to local conditions means sustainable ways in the fields of energy, material flows and public utilities. It includes local eco-technological solutions adopted by architecture and energy systems. While in rural areas, the improvement of environmental and cultural values and the enhancement of living conditions of their inhabitants are the chief concerns whereas the priority in large cities is to control 
and consciously harmonize the accelerating spread of urban land use (suburbanization).

\section{Local, regional identity - a diverse country}

Instead of a homocentric country where the rest of Nepal is pushed into the background by the dominance of its single centre and territorial diversity which is rich in areas with unique characteristics represents a more sustainable structure where people can feel strongly related to their own settlement, territory and region. To make this connection, it is necessary to reinforce the unique images of different areas to help local intellectual culture unfold and maintenance and renewal of natural and cultural resources everywhere across the country. Natural and cultural landscapes can to be preserved by transforming them into valuable assets to be protected and real resources for the local residents. Polycentric settlement network could serve to the protection and development of natural and cultural assets and the strengthening of regional consciousness with outstanding priorities.

\section{Territorial solidarity and equal opportunity}

In relation to territorial solidarity that better living conditions and quality of life is secured in order to provide people everywhere with equal opportunities that are also matching the specific regional and local potentials irrespective of whether they live in the core or in the periphery. Equal opportunities are defined not only for the national context but at lower levels as well. Consequently, national characteristics should be taken into micro-villages and isolated farmsteads deserve attention. Especially, the permanently backward areas with micro-villages situated in the remote rural areas of the country have facing the crisis. These regions are characterized by the accumulation of several negative factors: especially poor accessibility, the lack of real regional centers that could take care of their surrounding areas, unfavourable age and qualification structure of the population, disadvantageous economic structure and restricted availability of resources (shortage of capital, outmigration of the qualified labor force).

The socially, economically and physically erosive processes in these areas ultimately lead to the emergence of rural ghettos which gather social strata excluded from the labor market and the cities; while spatial separation of these areas means further constraints to their reintegration into the labor market. Areas dominated by micro-villages or farms are in difficult situation, and so are those areas which have a higher concentration of backward people. Many of these settlements are threatened by ageing and depopulation, while in other settlements with a high proportion of inactive population (with high dependency ratios), people face the risk of segregation and high fertility rates coupled with a high proportion of low-educated young people lead to the reproduction of poverty. Due to their unfavourable economic and social circumstances, these people neglect, and what is worse, are forced to use up their built and natural environmental and cultural assets. It is, therefore government initiation has to be taken to shift from the rural isolation and homocentric structure to polycentric structure of human settlement in order to extent the coverage of towns and cities with their functions as real centers.

\section{Dialogue for partnership}

Multi-level governance, participatory decision making together with partnership and cooperation is necessary to constitute real traditional norms of behavior. The territorial and cultural development approach determines social cohesion as a permanent and cooperative process involving the various actors and stakeholders of spatial development at political, administrative and technical levels.

In view of the Nepalese common understanding, it seems to be evident that spatial cohesion can be attained only through the cooperation of public and private sectors, the scientific community, the civil society (NGOs and non-profit organizations), and with the involvement of actors from various economic sectors while continuous and intensive dialogue is indispensable among all stakeholders. The existing diverse national traditions and capacities of governance across the country and these differences still influence practices in the regional level. The national urban development policy 2017clearly indicates that Nepal has to shift towards governance in the urban and rural municipal policies. In addition, the shift towards governance is urgent but it is the greatest challenges on the way towards governance face. Nepal is characterized traditionally by a somewhat rigid administrative structure and an (over-) regulatory state, with generally low commitment to rules (weak rule of law) and a powerless civil society. Social embeddedness of most institutions is weak.

Under such circumstances, it would be risky to directly and immediately weaken top-down regulation and shift towards new governance types based on partnership, openness, and consensusbased decision making. The shift towards new governance forms can only be a result of a long learning process, and a step-by-step transformation. Dissolving, loosening the traditionally top-down regulatory state in an artificial way could lead to an eastern type of new governance system, where corruption and the norms of rent-seeking behavior dominate and fill the emerging room for manoeuvre. Considering the over-fragmented municipal system, with a huge number of underfinanced municipalities lacking the appropriate resources to fulfill the huge number of tasks delegated to the municipal level. The challenges of this system are even increased by one-way financial mechanisms and the lack of resource sharing together with the generally weak willingness and culture to cooperate. There is hardly any real dialogue and cooperation among municipalities. Therefore, in this regard, the local level needs substantial reform and transformation in Nepal.

In this fragmented settlement system, micro-regions based on functional linkages could be the appropriate units of spatial development to enable cooperation and partnerships, and offer opportunities for dialogues between settlements. This is not (or hardly) working in Nepal partly because of the settlements themselves, who constantly compete with each other, and partly because of the unstable micro-regional system due to the constantly changing legal delineation of micro-regions. Furthermore, multifunctional, multi-purpose associations of micro-regions can be formed by local governments in order to perform some tasks 
of public services jointly, as well as their responsibilities related to micro regional spatial development (MOUD, 2016). Therefore, the new forms of territorial governance supporting territorial cohesion are still incomplete and imperfect and real decentralization and the realization of the principle of subsidiary are hampered by administrative and regulatory obstacles as well as by inappropriate norms of behavior and approaches. The realization of participatory and consensus-based decision making together with the application of new forms of territorial governance still poses a big challenge for the Nepalese practice, and this challenge is even greater concerning processes crossing (administrative or regional) boundaries.

\section{Development of the local economy, local markets}

The effects of globalization increasingly reach individual settlements and regions. They often find themselves in a rather vulnerable situation, and some rural areas of Nepal gradually lose their economic role. Especially in view of the current global financial and economic crisis, it is highly important to assign and implement development directions adapted to local conditions and resources. This includes also cooperation between enterprises, as well as economic processes generated with the involvement of local stakeholders evolving from bottom up along specific value-chains. Forming autonomous local and territorial systems can reduce the vulnerability of regions and their dependence on external resources. At the same time, intensive and partnership based territorial cooperation can help successfully reach external markets. By way of enabling a gradual shift from self-sufficiency and primary production to higher levels of the production valuechain in rural and disadvantaged areas, and by forming diversified agrarian economies in each landscape unit, the production of high-quality and marketable local products and the development of local brands can be attained. As a consequence, the significance of local markets will rise. In order to minimize transport costs and environmental pollution, it is necessary to promote a greater focus on production for local markets as this contributes to sustainable development.

The polycentric settlement development strategies, policies and plans are prerequisites for achieving the goal of sustainable development and national prosperity as expected in the constitution of Nepal. Polycentric centers not only promote agglomerative economies and facilitate economic growth; they also generate a disproportionate number of trips and promote accessibility network. It can be stated that policy supports that need to promote such polycentric settlement (urban system) development in order to improve the livelihood of the rural population and also meet the national goal of peace, prosperity, and sustainable progress. The polycentric settlement model as a sustainable development encourage housing development within the transit commute shed of these centers.

Such policies, combined with simultaneous expansion and coordination of transit service to existing employment centers, would serve to balance jobs and housing within the transit commute sheds and similarly serve the goals. This development strategy also promotes the careful coordination of province and national level budgetary systems to balance development within a centre's periphery. It is therefore, the development plan of the country has to encourage the concentration of economic and livelihood opportunities within superior settlement centers and encourage territorial development by promoting social innovation and cultural development of the centers as well as neighbours of the centers.

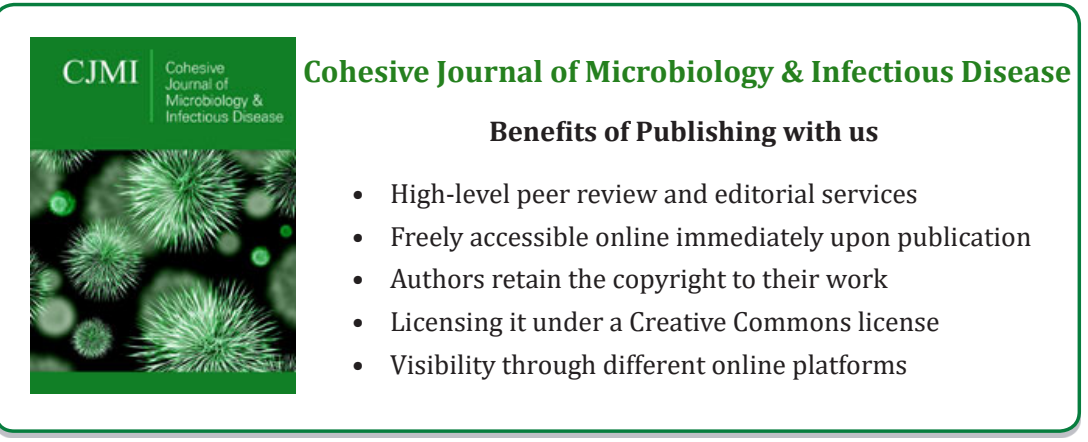

